\title{
AOR
}

Selected Papers of \#AolR2021:

The 22nd Annual Conference of the

Association of Internet Researchers

Virtual Event / 13-16 Oct 2021

\section{TAKING INTERDEPENDENCIES SERIOUSLY: THE CASE OF MOZILLA'S ENTANGLEMENTS WITH JOURNALISM}

\author{
Stefan Baack \\ Mozilla Foundation \& Weizenbaum Institute \\ Raul Ferrer-Conill \\ Karlstad University \& University of Stavanger \\ David Cheruiyot \\ University of Groningen
}

\section{Introduction}

The idea that journalism exists as a more or less autonomous professional field that is changing because it is increasingly becoming permeable towards 'outsiders' is widespread in journalism studies (Örnebring and Karlsson 2020). This can be illustrated by the numerous conceptual frameworks developed to describe the relationship between journalists and 'others', like 'interlopers' (Eldridge II 2019) or 'intralopers' (Holton and Belair-Gagnon 2018). Researching how digital journalism is changing due to the influence of online non-journalistic actors is important, but doing so exclusively (or primarily) takes a reductionist view of the much more complex interdependencies between journalism and other actors. When it comes to journalism's influence on others, we typically think of audience research or the dynamics between journalistic reporting and political actors or PR. To understand journalism's role in society, we argue that we should broadly ask how journalistic practices and related imaginaries about journalism influence all kinds of actors that make up today's digital news ecology.

To illustrate the value of this approach, we explore how imaginaries about journalism influence the practices and identity of Mozilla, an organization best known for the development of the web browser Firefox. Mozilla is currently in a phase where possible collaborations with, or support of journalism is actively explored. We argue that this exploration is shaped by how Mozilla imagines journalism, making it an interesting case study for our purpose. 


\section{Study rationale}

Theoretically, we combine two conceptual frameworks. First, we follow the nonfunctionalist and process-oriented figurational approach outlined by Couldry and Hepp (2017). Figurations describe relations of interdependence based on interlocking practices and shared meanings between disparate actors. Second, we adopt an institutional logics approach (Thornton, Ocasio, and Lounsbury, 2012) to investigate the connections between individual agency, cognitive processes, and socially constructed institutional practices and power structures as guiding logics of journalism and peripheral online organizations. We thus consider Mozilla's interrelatedness with journalism as fluctuating and continuously changing over time. Our aim is to show that interdependencies between journalism and Mozilla emerge around practices and are guided by their individual institutional logics.

Inspired by Yin (2018), we used a qualitative case study approach relying on a wide range of sources (in-depth interviews, self-identifying documents, blog posts and project homepages). The interviews were conducted online and lasted between 30 minutes and one hour. ${ }^{1}$ Interviewees were selected based on their role in Mozilla projects with clear connections to journalism. Our questions focused on exploring the relevance of the project for Mozilla, whether there were direct collaborations with journalists, and how particular imaginaries about journalism shaped the project.

\section{Mozilla and journalism: Exploring new ways to finance online content}

An important step in Mozilla's relationship with journalism is the recent update of the socalled 'Mozilla Manifesto' (Mozilla n.d.), a document outlining the values and goals of the organization. While the original Manifesto mostly adapted values from open source culture, it was expanded with an emphasis on the "quality of people's experiences online" in 2018, which included a commitment to diversity, "civil discourse", "reasoned argument", and "verifiable facts" (Baker 2018). There are clear connections between these values and typical associations with traditional Western notions of journalism as a provider of objective facts that facilitates political deliberation (cf. Hanitzsch and Vos 2018). The changes to the Manifesto created the basis for the idea that supporting organizations whose practices and values are compatible with the Manifesto and supporting Mozilla's own mission overlaps. This has created pathways for new connections to journalism. One example is Mozilla's efforts to develop and support alternatives to advertising as the dominant business model for online content.

Supporting alternatives to ad-driven business models is interesting for Mozilla because problems central to its own mission are seen as negative side-effects of online advertisement: privacy-invasive surveillance, misinformation or discriminatory algorithms. As one of our interviewees put it: advertising is "dominating how we experience the web. It's dominating even how content shows up on the web [...] there are lots of harms that have evolved". Journalists are perceived as potential partners in these endeavors. According to our interviewees, news publishers would be interested in lowering their dependencies on targeted ads and thus are open to experimentation.

\footnotetext{
${ }^{1}$ At the time of writing, two interviews had been conducted. We aim for up to ten interviews.
} 
An example for such an experiment is Mozilla's collaboration with Scroll ${ }^{2}$. Scroll is a USbased service where users pay a monthly subscription to browse partner websites from Scroll's network (like The Verge or The Atlantic) without advertisements. Partner websites are rewarded based on the time users spent on them. Mozilla collaborated with Scroll by offering a browser extension for Firefox that further reduced advertisements on partner websites and blocked trackers. The project enabled Mozilla to support a service that helped Scroll's partners, which are considered to provide 'Manifesto-compatible', fact-oriented journalism. Moreover, it allows Mozilla to support a revenue model that rewards time spent on websites, thereby supporting a different logic to finance journalistic content online.

This brief example illustrates how supporting journalism is considered aligning with Mozilla's mission because journalists are considered supporting the values outlined in the Mozilla Manifesto (like fighting disinformation). Supporting this idea of journalism by lowering news media's dependency on ad-driven business models in turn shapes Mozilla's own identity, as it is a way to differentiate itself from big tech companies that thrive on the dependency on targeted ads (like Google or Facebook), enabling Mozilla to act as an alternative partner to journalists.

\section{Conclusion}

These preliminary findings suggest that studying how particular imaginaries about digital journalism influence non-journalists can help illuminate journalism's role in today's digital news ecology beyond its 'democratic function' (Zelizer 2012). Importantly, they show sources of journalistic stability rather than change. In our case study, Mozilla is pushing journalism in a direction that supports its values, which suggest a fairly traditional idea of journalism. Findings like these can help develop a more nuanced understanding of the digital transformation as a process that both challenges and reinforces 'traditional' practices and identities.

\section{References}

Baker, Mitchell. 2018. 'Mozilla Marks 20th Anniversary with Commitment to Better Human Experiences Online'. The Mozilla Blog. Retrieved 25 August 2019 (https://blog.mozilla.org/blog/2018/03/29/mozilla-marks-20th-anniversarycommitment-better-human-experiences-online).

Couldry, Nick, and Andreas Hepp. 2017. The Mediated Construction of Reality. Cambridge, UK; Malden, MA: Polity Press.

Eldridge II, Scott A. 2019. "Where Do We Draw the Line? Interlopers, (Ant)Agonists, and an Unbounded Journalistic Field." 2019 7(4):11. doi: 10.17645/mac.v7i4.2295.

Hanitzsch, Thomas, and Tim P. Vos. 2018. 'Journalism beyond Democracy: A New

${ }^{2}$ https://web.archive.org/web/20210402081644/https://firstlook.firefox.com/betterweb/. 
Look into Journalistic Roles in Political and Everyday Life'. Journalism 19(2):14664. doi: $10.1177 / 1464884916673386$.

Holton, Avery E., and Valerie Belair-Gagnon. 2018. 'Strangers to the Game? Interlopers, Intralopers, and Shifting News Production'. Media and Communication 6(4):70-78. doi: 10.17645/mac.v6i4.1490.

Mozilla. n.d. 'The Mozilla Manifesto'. Retrieved 22 August 2019 (https://www.mozilla.org/en-US/about/manifesto/).

Örnebring, Henrik, and Karlsson, Michael. 2020. Journalistic Autonomy. Oxford Research Encyclopedia of Communication. https://doi.org/10.1093/acrefore/9780190228613.013.829

Thornton, Patricia H., William Ocasio, and Michael Lounsbury. 2012. The institutional logics perspective: A new approach to culture, structure, and process. Oxford, UK: Oxford University Press.

Yin, Robert. 2018. Case Study Research and Applications: Design and Methods. Newbury Park, CA: SAGE Publications Inc.

Zelizer, Barbie. 2012. 'On the Shelf Life of Democracy in Journalism Scholarship'. Journalism 14(4):459-73. doi: 10.1177/1464884912464179. 